\title{
Spirit Possession and Healing Cult among the Brasilian Umbanda ${ }^{1}$
}

\author{
Horst H. Figge
}

Umbanda is an animistic-spiritistic religion of Brazil with several million adherents especially in the bigger Cities. It may be characterized as an extraecclesiastic consolidation of popular catholicism within the vacant forms of ancient Afro-Brasilian sects. The central belief is the existence of all sorts of spirits; a central task is to give them the opportunity temporarily to take hold of human bodies. There may be a hundred thousand or more trained incorporation-mediums in Brazil by now, that is, people who in certain instances believe, and are thought by others, to be spirits.

The Umbanda groups meet once to three times a week, mostly at night and in their Centers, which resemble Catholic chapels. The groups consist of ten to 50 or more spirit mediums and of fewer assistants. All the different sessions are open to the public. Passive believers prefer by far those sessions in which they are given the possibility to enter into direct contact with the embodied spirits.

There are, roughly speaking, five categories of spirits called and embodied in Umbanda: deities of nature (who are seen in close connection to Catholic saints), old people, good and bad people of middle age, and children. All of them show a semi-standardized behavior. Personally known dead are seldom or never called.

There is no cult session at all without the presence of embodied spirits. The priest himself always is a medium and he leads the group and the sessions mainly through his different spirit roles. Every developed medium is the 'horse', as it is called, of at least one spirit of each category, generally of more. Mediums are free to incorporate any spirit, male or female of any category - or in the language of Umbanda: the spirits are free to choose any medium.

Umbanda does not know any organisation or leadership above the level of the thousands of cult-groups. Groups form around certain priests called 'chiefs' who train their mediums and later an ordain priests from among them. The new priests may form their own group or stay with their spiritual father or mother. The social background of members and of

${ }^{1}$ Erste Veröffentlichung in: Psychotherapy and Psychosomatics Vol. 25 (1975), S. 246250 . 
passive visitors, the behavior of the spirits, the display of special clothing, headgear, etc., may be different from group to group, depending on the preferences of the chief, respective his embodied spirits.

In well-organized groups the different categories of spirits are called one by one. If necessary, spirits appearing at the wrong moment, are more or less politely sent away. The sessions generally are accompanied and guided in every phase by songs and rhythmic clapping of hands or drumming, which means that songs and rhythms are specific, e.g. to certain categories of spirits or even to certain individual spirits.

A Session may last from 2-6 h or more. The sessions most appreciated by the mediums are festive ones in the open air: in the woods; at the seaside; on a street-crossing, etc., and they may last for a whole day or a whole night. Mediums may embody spirits for hours. The same way they are asked to incorporate, spirits are asked to retire, generally by songs. They may, however, retire spontaneously after taking adequate leave.

As the basic behavior of spirits of a certain category follows norms, so does the behavior shown at the alternation points between medium-role and spirit-role, the moment in which the spirit is thought to enter and to leave the body. Especially at the end of the possession most Umbandists must be helped by assistants, because otherwise they would seriously injure themselves. In the course of possession the assistant is a sort of servant to the spirit; however, he also sees to it that the spirit does not infringe the norms of Brazilian society and of the group, and that he does not damage his 'horse', etc.

The declared main object of Umbanda is to do charity. This, however, in the first place means 'spiritual charity' and 'charity done by spirits'. The greater part of passive believers come to the cult sessions only to be helped. They are not very much interested in a ritual they hardly understand, they have only superficial knowledge of the theological background.

We may distinguish four main kinds of treatment within Umbanda: countermagic, fluid manipulation, offerings and mediumship. Which one of those is prescribed in a given case depends on many things except on the problem itself as it is seen by us, the unbelieving. Unidentified pain, a badly healing wound, fear of dogs, lack of professional success may all be treated in the same way, but the headache of one person by a completely different method than the headache of another one.

The spirits are not at all interested in what trouble or disease a patient really has, what the real reasons are or the historical developments. They are almost exclusively interested in what the patient thinks he suffers, what he thinks the reasons are, and finally what he can be made to think of as 
an effective treatment. The diagnosis, if we may call it thus, is always orientated by given possibilities of treatment. As spirits only dispose of spiritual means, the troubles have to be explained spiritually to be accessible to the methods.

There raust be mentioned a possible exception, because sometimes spirits prescribe household medicine. But even in these cases the intention is mainly spiritual: they may prescribe a tea of orange leaves and garlic, and when the patient utters his aversion against garlic, make him pour it out in front of the main cross of a cemetery at midnight. I have several times witnessed spirits ordering believers to see a doctor and inquire whether directions given by doctors were followed. But 1 have also found pills and even catgut in offerings at the seaside.

(1) Countermagic. Nearly every Brazilian is convinced of the possibility of helping and harming people by unnatural means. The spirits generally confirm a patient's supposition to be the victim of a magic attack. The supposedly guilty person is rapidly found, when the patient names anyone he does not like. The spirit then invents a story of magic actions against the patient, which he can neutralize by stronger ones, and he is willingly helped by the patient who may have noticed something disturbing, the loss of a piece of cloth, a coloured ribbon in front of the door or the like. It is important that differences between offerings and actions of positive or negative magic and countennagic are mainly spiritual, which means they cannot be recognized, at least not by a common believer. Thus, the countermagic that one of them puts somewhere, may by erroneously considered harmful magic by the next one.

Actually there is quite a lot of destructive magic done too. But from the belief itself results that the person aimed at neuer perceives it, because otherwise he would be able to defend himself or even throw the spell back. Thus, results of black magic are possible only an the side of its originator and it actually may be considered one of the most lucky means of neutralizing aggressive tendencies.

(2) Fluid manipulation. Umbandists believe that there are two kinds of spiritual energy in everything that exists. Living beings, objects, acts, thoughts, everything, are loaded with a certain quantity of positive and negative fluid and irradiate them onto surrounding or connected bearers. Indicators of bad fluids are, e.g., filth, ugliness, bad luck, remorse; indicators of good fluids are the contrary. Frech air, daily bath, pleasing conversation, constructive thoughts, etc., augment the share of positive fluids. A positive balance of good fluids means well-being, contentment, freedom of pain and sorrow, etc. Only embodied spirits have the faculty to manipulate fluids directly. They do so mainly by so-called 'passes'. Giving passes, the spirit moves his hands along the body-contours of the patient, 
by which procedure bad fluids are thought to be drawn out. They are thought to condense within the body of the 'horse' and by the special forces of the spirit to be thrown out into the universe by finger snaps or the like. There are many variants of passes. Some spirits touch the patients more or less intensely, some even lift them up and whirl them around, some may intensely quiver all the time, giving the patient's head, his neck or other parts a vibration massage, still others prefer to treat with the smoke of their pipe or cigar or with water or brandy. Most of those procedures are accompanied by hardly understandable mutters of prayers, wishes and advices of unspecific content.

Believers do not show any visible result afterwards, but obviously they must be convinced of the efficacy, because they come for treatment week after week or at least when in trouble which they see in connection with a personal surplus of negative fluids. Also the mediums themselves like to get passes. The fully developed ones, however, are given passes only by their own spirits, that means the embodied spirits clean their own 'horse'. Closely related to fluid manipulation is what is called 'exchange of head'. Spirits claim to be able to take certain troubles, which are considered things that one has and that can be taken away from one person and given to another one. This may be done secretly onto a known - mostly an unknown victim - by magic acts. If it is done openly, the patient can observe a medium wince, be shaken by clonic twitches, fall to the ground, etc., because, as he is told, the bad substance moves from him to the body of the medium. The medium is cleaned by his own good spirits later on. Often the exchange of head is done with animals which are usually killed afterwards. Longer lasting protection against evil is thought to be given by certain types of necklaces with iron links and amulets prepared or at least blessed and loaded by spirits or, e.g., by a glas of water put behind the entrance door.

(3) Offerings. Quite often believers are instructed to offer candles, flowers, food, etc., to good spirits, to guarantee their help, or to bad spirits to calm down their temper and make them abstain from noxious influences.

Although only few believers know, the spirits generally put much more importance on the act of preparation, time and place of deposition, and especially to the patient's attitude, than to what is offered. It is amusing to see a poor patient bargain with the consulted spirit who may reduce his demand from seven black chickens to one brown one or even to three cheap cigars, as long as he is convinced of the patient's honesty.

(4) Mediumship. The treatment that interferes most with the life course of a patient is his development as a spirit medium. In the eyes of Umbandists, every human being has a lot of guiding and guarding spirits, the obligations against which, normally, are quite unimportant. In certain 
cases, however, it is believed that troubles are caused by those spirits as they want a person to develop into a medium and thus give them the oportunity to embody. Obviously this suggestion is only made when the chief (or his spirit) is willing to accept the patient as a member of his group. If the patient is not able to become a medium, e.g. because he cannot spare the necessary time or if he just does not want to, the way out is offerings. If he consents, he has to buy the cult clothes, accept certain regulations, and participate regularly in so-called developmental sessions. The training is allmost exclusively done by embodied spirits, so the trainee always has in front of him an example of how spirits are thought to behave through his body.

Most of the different techniques to eliminate the patient's primary personality by trance can be categorized in one of the two following possibilities: (a) continuous and increasingly contrary tendencies of behavior are activated, by systematic humiliation or the skillful use of a strong aversion, until suddenly the possibility of showing any behavior at all collapses. The patient may show abrupt, uncoordinated movements, more or less generalized convulsions, states of stupor or swoon; (b) within the atmosphere of expectation and fright in which the patient thinks himself surrounded by invisible beings, waiting for them to push him out of his own body, an instant is created in which he gets sure that the decisive moment has come and he cannot resist any more. He may be startled by a cry or suddenly be drawn off balance. It is a most amazing misinterpretation of sessions of spirit-possession cults, to speak of a hypnogenous situation. There is an ear-deafening noise in the generally overcrowded room, the trainee has to stand, sometimes he is even pushed and pulled around. As soon as he starts to stagger or show other symptoms of his soul leaving the body (as Umbandists would say) bystanders intensify their song, shout salutes to the spirit they believe is starting to embody.

Later an the newly embodied spirit, which does not show any behavior at all, is asked for blessings, called 'father', politely put in adequate positions, etc. And exactly the same way as a child's personality is created in the process of socialisation, without the educators knowing that they do not just form or modify a given object, the secondary personality comes into existence by supposed interaction. A difference lies in the fact that after the preliminary training the secondary personality may get access to contents of the primary personality, so the spirit need not learn all the particularities of his role, if and as his medium knows them.

The ability to fall into trance more or less spontaneously, and to embody a spirit conforming to the individually felt necessity of the moment, is guaranteed by what we may call internalization of the releaser. This and 
the avoidance of any possible rapport is brought about by the fact that nearly everybody in the cult group participates in the development of the new medium and by frequent and complete alterations of the general situation.

Furthermore, the development of mediums in and by the group guarantees that spirits do not enter into direct contact wich the medium's soul (via hallucinations or automatisms) at least not outside the adequate group situation.

Bibliography

Figge, H.H.: Geisterkult, Besessenheit und Magie in der UmbandaReligion Brasiliens (Alber, Freiburg/München 1973). 